\title{
LINGUAGEM E CONHECIMENTO, TEMA DA FORMAÇÃO INICIAL NA LICENCIATURA INTEGRADA EM CIÊNCIAS, MATEMÁTICA E LINGUAGEM
}

\author{
LANGUAGE AND KNOWLEDGE, THEME OF INITIAL TRAINING IN THE \\ INTEGRATED DEGREE IN SCIENCES, MATHEMATICS AND LANGUAGE
}

\author{
José Moysés Alves ${ }^{1}$ \\ ORCID iD: 0000-0003-1307-1249
}

Andrela Garibaldi Loureiro Parente ${ }^{2}$

ORCID iD: 0000-0003-3396-700X

\begin{abstract}
RESUMO
Este artigo relata a pesquisa de um professor sobre sua prática, ao ensinar o tema Linguagem e Conhecimento I, para uma turma de 40 licenciandos. O objetivo foi produzir novos sentidos sobre o ensino do tema, a partir da narrativa de uma tentativa de aproximar a formação proporcionada com a prática pedagógica desejada na atuação profissional, em uma perspectiva de simetria invertida. Além de discutirem seus conhecimentos prévios e alguns textos, os licenciandos pesquisaram assuntos relacionados ao conteúdo Natureza e Cultura do Marajó, planejaram atividades e elaboraram recursos didáticos para ensiná-lo a alunos dos anos iniciais, preocupando-se com a abordagem comunicativa. A narrativa da experiência tomou por base as memórias do professor, o planejamento realizado para o tema e as produções dos licenciandos. A análise interpretativa da narrativa possibilitou produzir os seguintes sentidos. É possível trabalhar com um tema teórico, na formação inicial de professores, em uma perspectiva de simetria invertida. A contextualização permite valorizar a identidade cultural e a história pessoal dos licenciandos, mobilizando suas emoções. O diálogo e o planejamento colaborativo de atividades, contribui para o desenvolvimento de vínculos afetivos, da criatividade e da autonomia dos futuros professores.
\end{abstract}

Palavras-chave: Linguagem e conhecimento. Docência no ensino superior. Formação inicial de professores. Simetria invertida. Reflexão sobre a prática

\begin{abstract}
This article reports a professor's research on his own practice, when teaching the theme Language and Knowledge I, to a class of 40 undergraduates. The objective was to produce new meanings about the teaching of the theme, from the narrative of an attempt to approximate the training provided with the pedagogical practice desired in professional practice, in a perspective of inverted symmetry. In addition to discussing their previous knowledge and some texts, the undergraduate students researched subjects related to Nature and Culture of Marajó content, planned activities and developed didactic resources to teach it to students in the early years, concerned with the communicative approach. The narrative of the

1- Doutor em Psicologia, Universidade de São Paulo (USP) Professor Titular - Universidade Federal do Pará (UFPA), Belém, Pará, Brasil. Endereço para correspondência: Travessa dos Tupinambás, 540/1204, Jurunas, Belém, Pará, Brasil, CEP: 660333-815, E-mail: jmalves@ufpa.br.

2- Doutora em Educação para a Ciência, Universidade Estadual Paulista (UNESP - Campus Bauru) - Professora Adjunta IV - Universidade Federal do Pará (UFPA), Belém, Pará, Brasil. Endereço para correspondência: Avenida Perimetral, 7, Residencial Jardim Universitário, Quadra 2, Casa 8, Guamá, Belém, Pará, Brasil, CEP: 66075-750, E-mail: andrelagaribaldi40@gmail.com.
\end{abstract}


experience was based on the teacher's memories, the planning carried out for the theme and the productions of the undergraduate students. The interpretative analysis of the narrative made it possible to produce the following meanings. It is possible to work with a theoretical theme, in the initial formation of teachers, in a perspective of inverted symmetry. The contextualization allows valuing the cultural identity and the personal history of the graduates, mobilizing their emoticons. Dialogue and collaborative activity planning contribute to the development of affective bonds, creativity and autonomy for future teachers.

Keywords: Language and knowledge. Teaching in higher education. Initial teacher training. Inverted symmetry. Reflection on own pratice.

\section{INTRODUÇÃO}

Como ensinar o tema Linguagem e Conhecimento na formação inicial de professores, tendo com eles uma experiência semelhante a que poderão ter, em sua atuação profissional futura, com estudantes dos anos iniciais? Procurando responder esta pergunta, um professor formador realizou uma pesquisa sobre sua prática (JOSSO, 2010; ANDRÉ, 2016), que relatamos no presente artigo. Investigamos, narrativamente (CLANDININ; CONNELLY, 2011), a experiência com uma turma de licenciandos, em sua primeira etapa de formação inicial. O planejamento e a reflexão sobre a experiência foram feitos colaborativamente pelos autores, mas para facilitar a leitura, o texto foi redigido na primeira pessoa do singular, por tratar-se de uma prática em que o primeiro autor era o professor da turma. Retomamos a primeira pessoa do plural nas Considerações Finais.

O tema Linguagem e Conhecimento I (LC I) é um componente do primeiro semestre da grade curricular da Licenciatura Integrada em Ciências, Matemática e Linguagens (LIECML) do Instituto de Educação Matemática e Científica (IEMCI), da Universidade Federal do Pará (UFPA). Conforme sua ementa, pretende apresentar e discutir diferentes definições de linguagem, noções sobre sua filogênese e ontogênese, a relação entre pensamento e linguagem, bem como sobre o papel da linguagem em diferentes métodos de ensino. O tema é retomado em semestres posteriores e novas discussões são introduzidas, considerando a especificidade da linguagem e da comunicação em aulas de língua portuguesa, matemática e/ou ciências. Embora o tema assuma desdobramentos em função da área de conhecimento, a interdisciplinaridade é um princípio pedagógico valorizado nesta licenciatura.

Ministrei o referido tema algumas vezes e estava insatisfeito, porque avaliava que não conseguia relacionar, diretamente, seu conteúdo ao trabalho do professor em sala de aula. Ouvia falar da simetria invertida (CNE/CP, 2002; OLIVEIRA; BUENO, 2013) em que o professor formador ensina o licenciando de maneira semelhante a como ele poderá proceder com seus 
alunos. Entretanto, não sabia como realizar isso no tema LC I, por se tratar de uma discussão eminentemente teórica e por não ser um assunto abordado com os alunos dos anos iniciais.

Ao ministrar o tema, costumava apresentar noções teóricas, relatos de pesquisa sobre a comunicação professor-alunos e exercícios de análise de transcrições de interações verbais ocorridas em aulas, relatadas na literatura (ex. FONTANA, 1993; SCARPA; TRIVELATO, 2001), mas continuava com a sensação incômoda de corroborar com a ausência de relação entre disciplinas pedagógicas e disciplinas de conteúdo específico. Esta falta de comunicação entre as disciplinas é criticada por fazer parte do modelo da racionalidade técnica. Neste modelo se entende que os problemas de aprendizagem devem ser resolvidos por um especialista, desconsiderando a capacidade dos docentes para solucioná-los, articulando, criativamente, conhecimentos específicos e pedagógicos. (CONTRERAS, 2002; GATTI, 2013; GATTI et al., 2019).

Compartilhei tal incomodo com uma professora de Ciências, também docente da LIECML. Contei a ela que estava em busca de um assunto que me permitisse aproximar o tema LC I dos conteúdos das séries iniciais e, consequentemente, do trabalho do licenciando, na perspectiva de sua atuação profissional. Ela me sugeriu trabalhar com o conteúdo Natureza e Cultura (NC), por considerar um assunto relevante, que consta do currículo dos anos iniciais, integrando várias áreas de conhecimento. Avaliei a proposta pertinente e interessante. Nossa colaboração se estendeu deste momento em diante, até a redação do presente artigo.

\section{REFERENCIAL TEÓRICO}

Considerei a proposta da professora pertinente, porque, além de Natureza e Cultura ser um conteúdo dos anos iniciais, era um assunto para o qual eu, com formação na área de psicologia, me achava minimamente preparado. Tinha estudado sobre etologia humana, orientado alguns trabalhos de professores de biologia e participado de algumas bancas, de mestrado e doutorado, nas quais se discutia, por exemplo, a noção de ambiente, não como algo que afeta o homem desde o exterior, mas como contexto do qual o homem faz parte e com o qual se compromete de forma responsável (SANTANA, 2004; OLIVEIRA, 2010; MORAES, 2015).

Além disso, considerei a proposta interessante, porque o tema Linguagem $\mathrm{e}$ Conhecimento está intimamente relacionado com o conteúdo Natureza e Cultura. Nossa linguagem simbólica estrutura nossos modos de vida e é um traço distintivo do homem entre os 
outros animais. O estudo da evolução humana registra mudanças no tamanho e formato do cérebro dos nossos ancestrais, bem como a progressiva sofisticação das ferramentas de pedra. Tais mudanças, provavelmente, estão relacionadas ao desenvolvimento da comunicação social, desde uma comunicação através de gestos expressivos, compreensíveis apenas na situação presente, até uma comunicação através de palavras com significados específicos, capaz de sustentar uma organização social complexa exigida, por exemplo, pelo modo de vida caçadorcoletor. Uma linguagem capaz de libertar o homem da situação imediata e possibilitar o planejamento de sua ação coletiva futura. Assim, além dos fatores naturais, contribuíram para a evolução humana suas próprias criações, sua cultura, incluindo seu conhecimento tecnológico e sua linguagem (LEAKEY, 1995; LURIA, 1987).

Outra coincidência também me fez ficar entusiasmado com a proposta. Costumava usar em minhas aulas a transcrição de um episódio, analisado por Fontana (1993), em um capítulo que trata sobre a elaboração conceitual na sala de aula. O episódio transcreve a interação verbal de uma professora com sua turma de $3^{\mathrm{a}}$. série do ensino fundamental, em uma aula sobre o conceito de cultura. Esta aula acontece dentro de uma sequência didática, envolvendo outras atividades, como a visita a uma exposição sobre cultura indígena, em um museu. A discussão é feita a partir de uma gravura que retrata a vida em uma aldeia indígena, incluindo diferentes atividades. Inicialmente, a professora pergunta o que as crianças estão vendo na figura e elas descrevem vários objetos e atividades. Em seguida, ela pede que apontem e justifiquem o que faz parte da cultura indígena. Ao fazer isso, as crianças explicitam diferentes concepções de cultura e as discutem. Por último, a professora pede que as crianças apontem o que faz parte da natureza e as crianças também tem oportunidade de discutir e aprender sobre a relação entre natureza e cultura.

A próxima vez que ministraria o tema LC I seria para uma turma nova da LIECML, em Soure, cidade situada na Ilha do Marajó, no Estado do Pará. Então, pensei em trabalhar com a turma a temática Natureza e Cultura do Marajó. O Marajó tem uma biodiversidade exuberante e uma cultura riquíssima, que preserva algumas características dos antigos habitantes da região, expressando-se de várias formas, entre outras, em seu artesanato, culinária, esportes, lendas, brincadeiras e religiosidade. 


\section{METODOLOGIA}

Neste estudo, inspirado na pesquisa narrativa (CLANDININ; CONNELLY, 2011), analiso, interpretativamente, minha experiência docente em Soure, inferindo relações entre a formação proporcionada e a prática pedagógica desejada para a futura atuação docente, em uma perspectiva de simetria invertida. Modifico minha maneira de ensinar o tema Linguagem e Conhecimento I, com a introdução da discussão sobre Natureza e Cultura do Marajó e, a partir do envolvimento e da reflexão estabelecida com os licenciandos, produzo novos sentidos para o ensino do referido tema, ressituando meu papel de formador de professores (GATTI, 2013; GATTI et al., 2019).

De acordo com Clandinin e Connelly (2011), a pesquisa narrativa está orientada para a experiência docente. Ela é entendida como um processo contínuo de produção de sentidos e compartilhamento de vivências, na trajetória formativa dos envolvidos. Compreende que, a partir de suas experiências de ensino, o professor pode elaborar novos sentidos, que se tornam evidencias de suas aprendizagens. Nesta perspectiva, assumir a pesquisa narrativa para investigar minha prática e produzir novos sentidos para o ensino do tema LC I, se constitui um processo autoformativo (JOSSO, 2010).

A elaboração de novos sentidos relaciona-se aos movimentos que o pesquisador realiza, observando as dimensões que constituem o espaço tridimensional da pesquisa. Em primeiro lugar, o social. Nenhuma experiência pessoal se desenvolve sem considerar as interações com o outro. Em segundo lugar, o tempo. A experiência que nos propomos investigar no presente tem suas origens e motivações em situações do passado que, ao serem problematizadas, ajudam a projetar o futuro. Por último, o contexto. As relações que se configuram na narrativa não podem ser destacadas da paisagem, que o pesquisador reconstrói e torna visível no percurso de sua formação (CLANDININ; CONNELLY, 2011).

Era a primeira etapa da turma da LIECML em Soure. Frequentaram o tema 40 licenciandos, sendo 22 homens e 18 mulheres. Os licenciandos já tinham cursado outros temas em julho e agosto de 2018. O nosso era o último, na terceira semana de agosto. Depois, eles só voltariam a ter aulas nos meses de janeiro e fevereiro. Os temas tiveram, em geral, duração de uma semana, sendo oito horas de aula por dia. 


\section{RESULTADOS E DISCUSSÃO}

Ouvi elogios à turma feitos pelos professores que me antecederam. Logo que cheguei, conversei com os licenciandos e eles também elogiaram os professores formadores e as maneiras diferenciadas como realizaram as atividades, variando os contextos das aulas e as formas de abordar os assuntos, despertando o interesse e valorizando a criatividade dos professores em formação inicial.

A turma simpatizou com a proposta de trabalhar a temática Natureza e Cultura do Marajó. Desde a primeira aula, explicitei que o trabalho final seria o planejamento de atividades para ensinar aos alunos dos anos iniciais, conteúdos que relacionassem natureza e cultura, que fossem contextualizados no Marajó e que aproveitassem as ideias de nosso tema (LC I) no planejamento das situações comunicativas com os estudantes.

No primeiro dia, eles responderam, por escrito, o que entendiam por natureza, cultura e a relação entre ambas. Depois, se reuniram em grupos (de quatro ou cinco), discutiram suas respostas individuais e chegaram a uma resposta de consenso do grupo, para cada pergunta, que também registraram por escrito. No final da manhã, fizemos uma roda de conversa e discutimos as respostas. O diálogo foi animado, com manifestações de quase todos os licenciandos.

Ao definirem natureza, a maioria dos licenciandos mencionou o ambiente que nos rodeia, incluindo a fauna e a flora. Alguns consideraram que era algo que tinha uma origem própria, imutável e que existe sem a intervenção do homem. Outros explicitaram que a natureza inclui o homem e que pode ser influenciada por ele. Enfatizei esta última ideia na discussão com a turma.

Ao definirem cultura, a maioria dos licenciandos considerou as crenças, valores e costumes de uma região, que são transmitidas de uma geração a outra. Alguns mencionaram que ela é parte da identidade de um povo, constituída de saberes tradicionais, conhecimentos de pessoas antigas, sendo práticas que se propagam por um longo tempo. Depois da exposição das respostas dos grupos, chamei a atenção para o fato da cultura ser permanentemente recriada, sendo um processo vivo, que também incorpora inovações (GONZALEZ REY, 2002), aspecto que não havia sido explicitado nas respostas apresentadas.

A respeito da relação entre natureza e cultura, diferentes dimensões foram abordadas pelas equipes, indicando, algumas vezes, oposição entre as duas e, outras vezes, a influência de uma sobre a outra. 
Transcrevo a seguir as respostas de duas equipes que apontaram a influência da natureza sobre a cultura. Entre parênteses acrescentei as iniciais dos nomes dos licenciandos.

\begin{abstract}
A relação que fazemos entre natureza e cultura é que a natureza não dá chance de escolha ao homem, já a cultura sim. Natureza é fonte de vida, cultura é produto do trabalho humano, esta última estando diretamente conectada a homem, pois o que a natureza produz a cultura não, apenas faz uso dela. (Resposta da equipe: IB, NM, RA, FS e JS)
\end{abstract}

Muitas culturas estão ligadas ao ambiente em que elas fazem parte. Então a cultura e a natureza estão sempre mantendo uma certa relação, da feita que a natureza interfere nos aspectos culturais de cada região.

(Resposta da equipe: FR, LP, MS eWA)

A seguir, transcrevo as respostas de duas equipes que apontaram a influência da cultura sobre a natureza.

\footnotetext{
Embora tenham sentidos opostos, natureza e cultura estão interligados em vários contextos. De certa forma, a cultura de um povo acaba influenciando na natureza do indivíduo que ali se insere através de suas tradições e conhecimentos.

(Resposta da equipe: CK, EP, LQ e PR)

Acreditamos que a cultura nada mais é que uma maneira para o homem tentar entender e dominar a natureza a seu redor, com elementos extraídos da natureza (vestimentas, comidas, remédios caseiros, entre outros.

(Resposta da equipe: EB, EJ, BS, LL, WH e WQ)
}

Durante a discussão, argumentei que ambas as possibilidades acontecem e que também poderíamos notar isso no caso da evolução humana, que estudaríamos posteriormente. Assim, por exemplo, de um lado, um aspecto da natureza biológica do homem, o bipedalismo e a consequente liberação das mãos, influencia na fabricação e uso de ferramentas de pedra, uma prática cultural. Por outro lado, o domínio do fogo e o cozimento dos alimentos, que são práticas culturais, influenciam na biologia humana, entre outras, pela mudança na estrutura dos dentes (perda dos caninos proeminentes).

A discussão sobre os conhecimentos prévios dos licenciandos, a respeito de natureza e cultura, com os colegas e com a turma toda, incluindo o professor, foi um exercício de diálogo em sala de aula, que poderá inspirá-los a fazer semelhante com seus alunos. De acordo com Mortimer e Scott (2002), para Bakhtin, o diálogo é uma discussão em que diferentes perspectivas comparecem, sem que uma se sobreponha à outra. Na prática de muitos professores dos anos iniciais e também de seus formadores, prevalece a abordagem comunicativa não interativa ou interativa, mas de autoridade (conforme foram definidas pelos autores), em que só uma perspectiva predomina, geralmente aquela retirada do livro didático, que é sustentada pelo professor. 
Neste primeiro dia, à tarde, trabalhamos com o episódio analisado por Fontana (1993), que descrevi anteriormente. Solicitei aos licenciandos que dividissem a transcrição da interação verbal em partes, levando em conta as diferentes solicitações da professora. Ocorreram, inicialmente, diversas opiniões sobre a quantidade de partes em que o episódio poderia ser dividido. Depois de uma discussão, todos concordaram que seria adequado dividi-lo nas três partes antes mencionadas, a saber, a primeira, o momento em que a professora pede que os estudantes descrevam a gravura, depois, quando ela solicita que eles apontem e justifiquem o que é da cultura dos índios e, por último, o que faz parte da natureza.

Durante esta atividade, além do papel das instruções da professora para o encaminhamento da aula, destacamos as definições de cultura e natureza explicitadas no diálogo, apontando diferenças entre o conceito científico escolar e conceitos cotidianos, construídos a partir de generalizações empíricas pelas crianças. Segue um trecho da transcrição da aula como ilustração.

(48) Ric.: Aqueles dançando é cultura...

(49) Her.: Não... Não é não...

(50) Profa.: Por quê, Her.?

(51) Her.: Porque cultura não se mexe...

(52) Ric.: Mas você não tá lembrado que a tia disse que a música a gente não vê, não pega e é cultura?

(53) Profa.: Por que é cultura?

(54) Rog.: Porque é trabalho.

(55) Mar.: Dançar não é trabalhar...

(56) JProfa.: O que é trabalho?

(57) Ric.: Não... Não é isso... É porque a dança é o homem que faz

Fonte: Fontana (1993)

Na transcrição do episódio também é explicitado um exemplo da relação entre natureza e cultura, apresentado a seguir, que nos ajudou a retomar a discussão com os licenciandos sobre o mesmo assunto.

(67) Profa.: O que é natureza para vocês?

(68) Her.: Coisa que Deus fez.

(69) Profa.: O que é natureza no desenho?

(70) Her.: As árvore, os passarinho..

(71) Mas tia, o índio pega a árvore pra fazer canoa, pra fazer a casa... Árvore é cultura.

(72) Profa.: Ric., o índio faz a árvore ou usa a árvore?

(73) Ric.: Mas a gente não planta a semente?

(74) Profa.: grande sacada, Ric.! Isso mesmo, a gente planta a semente e da semente nasce a árvore. Mas quem faz a semente? O homem ou a árvore?

(75) Ric.: A semente é a árvore...

(76) Profa.: A árvore faz a semente sem precisar do trabalho do homem. Aí ela é natureza. Quando o homem planta semente e usa a árvore, daí ela pode fazer parte da cultura. Plantar e cuidar do crescimento e desenvolvimento das plantas é a agricultura...

Fonte: Fontana (1993) 
Esta foi uma oportunidade que os licenciandos tiveram, em nosso tema, de analisar, intencionalmente, a comunicação em uma aula. Durante a discussão dessa atividade, notamos a importância da linguagem para a construção do conhecimento, tanto na interação da professora com os alunos, quanto na interação entre os alunos.

Em seguida, cada licenciando expressou, por escrito, o que entendia por linguagem, conhecimento e como ambos se relacionam. Depois, todos socializaram com a turma suas opiniões individuais e conversamos sobre elas.

Ao definirem linguagem, a maioria dos licenciandos mencionou aquilo que o homem usa para comunicar ideias e sentimentos, transmitir o que sabe, de forma verbal ou não verbal, oral ou escrita. Alguns se referiram a signos ou símbolos, conceitos que retomamos na aula do dia seguinte.

Ao definirem conhecimento, a maioria dos licenciandos mencionou que é tudo aquilo que alguém aprendeu e sabe, podendo transmitir para outro. Alguns se referiram ao conjunto de informações adquiridas por meio da experiência e/ou acumuladas e guardadas na mente. Um licenciando referiu-se ao que se constrói a partir da interação com o meio. Outro mencionou a aprendizagem de determinado conteúdo. Um terceiro, argumentou que conhecimento não era só aquilo que era aprendido na escola, também o que era aprendido a partir da experiência, das tradições, da observação de profissionais trabalhando. Manifestei concordância com todas as ideias apresentadas, mas problematizei a noção de tomar informação e conhecimento como sinônimos, também a ideia de acumulação e armazenamento de informações. Essa discussão foi retomada no dia seguinte, a partir da fala de um filósofo, em um vídeo apresentado à turma.

Sobre a relação entre linguagem e conhecimento, a maioria expressou que o conhecimento pode ser transmitido através da linguagem. Alguns admitiram, além disso, que a linguagem também está implicada na produção do conhecimento. A resposta que transcrevo a seguir expressa essa ideia.

O conhecimento é algo que pode ser alcançado, adquirido e pode ser construído. A linguagem por sua vez e um instrumento para se construir tal conhecimento. Nesse sentido, a produção de conhecimento só é possível porque a linguagem implica essa condição.

(Resposta do licenciando FA).

Destaquei essa ideia durante a nossa discussão, lembrando Vygotsky (1987) quando argumenta que a linguagem, além de veículo da comunicação é instrumento do pensamento.

No dia seguinte, assistimos dois vídeos curtos, disponíveis no You Tube. O primeiro, intitulado "O que é linguagem?” (UNIVESP, 2008), exibe conversas com vários especialistas 
da área sobre definições, tipos e funções da linguagem, entre outros assuntos. Destaquei, na discussão com a turma, uma das definições de linguagem, explicitada pelo linguista José Luis Fiorim, no vídeo, que transcrevo a seguir.

Linguagem é o conjunto estruturado de signos, que se combinam de uma determinada maneira, com vistas à comunicação humana.

Fonte: UNIVESP (2008)

O segundo vídeo, intitulado "Conteúdo e conhecimento" (PROVOCAÇÕES FILOSÓFICAS, 2017), é parte de uma palestra de Mario Sérgio Cortella, em que o autor diferencia informação de conhecimento, argumentando que a informação é a base do conhecimento, pode ser acumulada e memorizada, mas é esquecida com facilidade. $\mathrm{O}$ conhecimento é o que importa para o sujeito, é aquilo que ele toma para si, o que o torna inesquecível. O conhecimento não é cumulativo, mas seletivo. Nesta perspectiva, o autor diferencia estudar de decorar informações.

Depois, tentei responder algumas perguntas dos licenciandos a respeito da definição de signo e do papel da linguagem na constituição do sujeito, a partir da perspectiva históricocultural, assuntos que foram mencionados, brevemente, nos vídeos. Vygotsky (1984) assemelha instrumento e signo por serem mediadores da atividade humana. Mas os diferencia, porque o instrumento se interpõe entre a ação e seu objeto (é dirigido externamente), enquanto o signo se interpõe entre uma ação e outra ação (é dirigido internamente). O signo media a relação do homem com outro homem ou consigo mesmo. É a partir da internalização da linguagem falada (ou gesticulada), que se estruturam os outros sistemas de signos. Assim, o homem tem a possibilidade de regular suas ações e refletir sobre elas, tornando-se consciente de si mesmo.

Neste tema, por ser um tema inicial, não pretendi discutir em profundidade uma perspectiva teórica. Minha intenção foi mais a de levantar e problematizar os conhecimentos prévios dos futuros docentes, acrescentando alguns elementos teóricos que lhes permitissem formular novas perguntas e sistematizações. Eles receberam textos para estudarem mais sobre esses assuntos.

Neste segundo dia, à tarde, eles leram sobre a evolução da espécie humana (CUNHA; MONTANARI, 1995). Poucos tinham ouvido falar sobre este assunto, mas demostraram interesse em conhecê-lo. O texto descreve características de nossos ancestrais hominídeos, bípedes, desde as diferentes espécies de Australopithecus, passando pelo Homo Habilis, que primeiro usou instrumentos de pedra e, em seguida, o Homo Erectus, que primeiro praticou a 
caça de animais de grande porte, dominou o fogo e aventurou-se a explorar territórios além da África. Este ancestral, dominava provavelmente uma linguagem mais complexa do que simples gestos compreensíveis apenas em um contexto perceptual imediato. Suas ferramentas de pedra eram mais sofisticadas, o tamanho do cérebro se aproximava ao da nossa espécie $\left(1.100 \mathrm{~cm}^{3} \mathrm{X}\right.$ $1.300 \mathrm{~cm}^{3}$, em média) e a organização social de caça e coleta exigia uma linguagem sofisticada. O texto caracteriza ainda o Homo Sapiens de Neandertal, cujo formato do crânio era um pouco diferente do nosso, seu aparelho fonador era comparável ao de uma criança humana de seis anos e ele foi o primeiro a enterrar seus mortos. Finalmente a nossa espécie, Homo Sapiens Sapiens, a primeira a produzir obras de arte, o que alguns autores consideram a única evidência segura da presença de uma fala articulada (LEAKEY, 1995).

Do término desta tarde em diante, focalizamos no planejamento e elaboração do trabalho final. Tinha comigo alguns livros didáticos dos anos iniciais, que os licenciandos consultaram para ajudá-los a definir um assunto para o trabalho, dentro do tema geral Natureza e Cultura do Marajó.

No terceiro dia, era feriado municipal em Soure, mas nós combinamos de investir o tempo no desenvolvimento do trabalho. Fizemos uma escala de rodízio e orientei cada equipe, problematizando o assunto escolhido para adequá-lo ao interesse do nosso tema. Incentivei e sugeri desdobramentos e procedimentos para a realização do trabalho final. No tempo restante, fora de nosso local de encontro, eles continuaram suas pesquisas sobre os conteúdos escolhidos, realizaram entrevistas, construíram recursos didáticos, entre outras atividades.

Nesta ocasião, também aconteceu algo que poderia inspirar os licenciandos a fazerem de forma semelhante com seus alunos. O diálogo, durante a orientação dos trabalhos, em que várias ideias trazidas pelos licenciandos foram valorizadas e outras foram sugeridas a eles, em uma troca intelectual genuína, cheia de entusiasmo, curiosidade e imaginação.

Os assuntos escolhidos pelos licenciandos foram: As plantas na cultura marajoara; Vertebrados e invertebrados do Marajó; O caranguejo na natureza e na cultura do Marajó; Corrida de resistência do cavalo marajoara; Tipos de rocha: usos na cerâmica marajoara; Resgate das lendas e brincadeiras tradicionais marajoaras e A luta marajoara.

Planejar os temas demandou dos licenciandos imaginação e criatividade, que nosso diálogo desenvolveu, na medida do possível. Não bastava o interesse pelo tema, era preciso que, no planejamento das atividades, eles não enfatizassem o polo da natureza ou da cultura, mas captassem a relação entre ambas. Era necessário resgatar o conhecimento popular, por exemplo, de como tirar caranguejo, usar plantas medicinais e interpretar os desenhos da 
cerâmica marajoara, também era preciso relacioná-lo aos conteúdos de ciências dos anos iniciais. Além disso, era importante pensar nas situações de comunicação que seriam propostas para motivar as crianças a aprender, possibilitando aos futuros professores atingirem seus objetivos.

Cada equipe se preocupou com a natureza das atividades que proporiam às crianças. Neste momento, notei o aproveitamento de outros temas da Licenciatura Integrada, cursados anteriormente pelos licenciandos, nos quais eles também aprenderam a confeccionar recursos didáticos, inclusive editar vídeos, preocupando-se em despertar a curiosidade e incentivar a participação das crianças.

Interessante notar o papel da motivação e da imaginação no planejamento das atividades. Os licenciandos tinham histórias relacionadas aos assuntos. Alguns tinham experiências pessoais ou familiares com a luta marajoara, o uso de plantas medicinais e a coleta de caranguejos, por exemplo, e falavam a respeito das mesmas com entusiasmo. Situar o tema na natureza e cultura do Marajó, implicou subjetivamente os professores em formação inicial e foi uma condição de produção de sentidos subjetivos (MITJÁNS MARTINEZ; GONZÁLEZ REY, 2017) sobre o aprender e o ensinar.

De acordo com a teoria da subjetividade de Gonzalez Rey e Mitjans Martinez (2017), os tipos de aprendizagem desejáveis ocorrem quando o sujeito personaliza as informações. Ele produz sentidos subjetivos, mobilizado suas emoções e processos simbólicos. Isto acontece na aprendizagem compreensiva, na qual o sujeito interpreta a informação recebida à luz de sua experiência pessoal e também na aprendizagem criativa, em que, além de personalizar a informação recebida, ele a problematiza e transcende, produzindo ideias novas.

Em dois dias, todas as equipes conseguiram pesquisar sobre os temas, planejar atividades e construir recursos didáticos para ensiná-los, além de produzirem uma apresentação em power point, com informações valiosas e bem ilustradas. A maioria das equipes produziu pequenos vídeos contendo entrevistas feitas com personalidades locais, incluindo artista, curandeiro, catador de caranguejo, ex-campeão da corrida marajoara, e/ou relatando processos desenvolvidos pela própria equipe, como por exemplo, extrair a tinta preta do jenipapo ou narrando a lenda do vaqueiro Boaventura. Outros trouxeram para a sala de aula plantas, argila e amostras de rochas. A maioria das equipes produziu recursos didáticos para ensinar e/ou avaliar o conteúdo proposto, usando jogos, principalmente. A título de ilustração, seleciono detalhes de alguns dos trabalhos a seguir. 
No trabalho "Tipos de rocha e seus usos na cerâmica marajoara", depois de classificarem as rochas em magmáticas, metamórficas e sedimentares, a equipe apresentou um slide intitulado "A argila como matéria-prima da cerâmica marajoara" com fotos de jarros e o comentário "A cerâmica marajoara, feita pelos indígenas da Ilha do Marajó, é a mais antiga dentre as artes em cerâmica do Brasil”. Em outro slide, apresentaram uma foto de latas com tinta e o comentário "As cores dadas às peças em arte marajoara, são extraídas de rochas sedimentares da região".

No trabalho "Natureza e cultura nos desenhos marajoaras", entre outras atividades, a equipe planejou entregar às crianças fotografias de peças cerâmicas e pedir que elas pesquisassem o seu significado. Explicaram que nesse tipo de cerâmica são sempre representados dois animais. Um do lado exterior do prato (suas bordas) e outro no seu interior. A cada um dos animais é atribuído uma qualidade. A Figura 1, abaixo, ilustra uma das peças e seus significados, obtidos pela equipe com um artesão local, que as confeccionava e conhecia o significado dos desenhos.

Figura 1 - Peças do jogo construído no trabalho da equipe sobre desenhos marajoaras

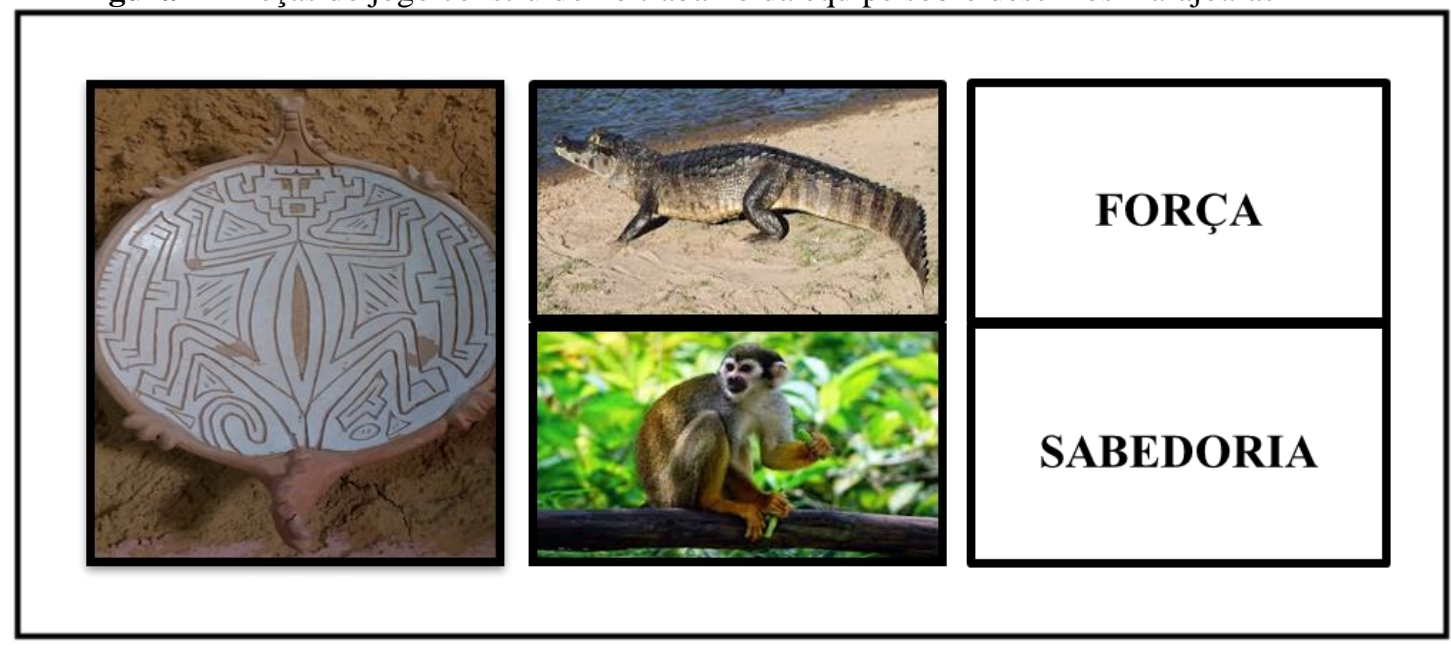

Fonte: Trabalho final da equipe para o tema LC I (2018).

No trabalho sobre "As plantas na cultura marajoara", as plantas foram classificadas como: usadas em tratamentos medicinais de curandeiros (garrafadas, chás e banhos), nocivas (comigo ninguém pode, urtiga, alamanda e espada de São Jorge) e usadas na alimentação (mandioca, jambu, urucum e macaxeira). A equipe apontou vários alimentos feitos com cada uma dessas plantas. Entre outras informações sobre as plantas nocivas, comuns na cidade, a equipe destacou a espada de São Jorge, que muitas crianças cortam ou arrancam do chão e usam em suas brincadeiras, podendo causar sérias irritações na pele. Produziram um recurso didático para avaliação da aprendizagem, confeccionado em um papel cartão, com bolsos referentes a 
cada uma das classes de plantas mencionados. As crianças receberiam fotografias das plantas e deveriam classificá-las, depositando a foto no bolso correspondente.

No trabalho sobre "Vertebrados e Invertebrados do Marajó" a equipe criou um jogo com figuras obtidas na internet de animais comuns na região, sendo 28 de vertebrados e 28 invertebrados. Um número igual de cartas foi confeccionado contendo a letra "V" ou a letra "I". Além disso, para cada animal foi confeccionada uma carta com dicas a ele relacionadas e que tinham a ver com sua natureza ou uso na cultura. A equipe criou regras para o jogo. Venceria o jogo quem juntasse o maior número de trios de cartas com figuras, letras e dicas. A equipe produziu um vídeo ilustrando as regras do jogo.

Planejar atividades e produzir recursos didáticos são tarefas que os licenciandos precisarão realizar, cotidianamente, quando estiverem no exercício da profissão. Implica estudar o conteúdo, pensar em formas de comunicação para conhecer o que os alunos sabem sobre o assunto, discutir essas ideias e ampliá-las. Também demanda que aprendam a interagir para conhecer os interesses dos alunos, despertar a curiosidade deles, gerenciar suas atividades em grupo, orientá-los em suas pesquisas, desenvolvendo sua imaginação e criatividade. Acredito que cada licenciando teve oportunidade de vivenciar esses tipos de interações, na condição de aluno, tendo oportunidade de avaliar a relevância das mesmas para sua aprendizagem e, talvez, para a aprendizagem de seus futuros alunos.

No quarto dia, pela manhã, eles terminaram de elaborar suas apresentações e de tarde começaram as comunicações dos trabalhos para a turma. Cada equipe teve uma hora para apresentar o seu trabalho. As apresentações foram sempre entusiasmadas e divertidas, incluindo momentos que envolviam os demais colegas da turma em simulações e brincadeiras. Esta atividade se estendeu até o final do quinto dia.

Falar em público, apresentar ideias e mobilizar a audiência para interagir, de forma dialógica e lúdica, são outros exemplos de habilidades importantes que o professor precisa desenvolver, desde sua formação inicial.

\section{CONSIDERAÇÕES FINAIS}

Acreditamos que o tema proporcionou condições para a aprendizagem e desenvolvimento de conceitos complexos como natureza, cultura, linguagem e conhecimento. Certamente estes conceitos serão retomados e aprofundados nos outros temas homônimos subsequentes (Linguagem e Conhecimento II, III, IV e V) e em outros eixos da LIEMCL. 
Consideramos adequado, em um tema inicial (LC I), levantar e valorizar os conhecimentos prévios dos estudantes, discuti-los, trazer alguns elementos teóricos novos, pesquisar, imaginar e construir recursos pedagógicos para facilitar a comunicação dialógica em sala de aula.

Fica para nós o desafio de trabalhar, desde o primeiro tema, com uma concepção que relacione linguagem, conhecimento e subjetividade. Isto porque entendemos, inspirados na teoria da subjetividade, que a linguagem é mais que um sistema estruturado de signos e que o conhecimento não é simplesmente o resultado de operações cognitivas. A linguagem em uso é sempre constituída de processos simbólicos e emoções. Expressa sentidos subjetivos constituídos na história de interações do sujeito nos vários contextos sociais dos quais participa. A produção do conhecimento, apoiada na linguagem, também é um processo subjetivo, no qual estão implicadas as emoções e a imaginação do sujeito, não é um processo neutro (GONZÁLEZ REY, 2014). Esta concepção tem implicações importantes para o ensino e a aprendizagem em ciências, discutidas por nós em outros trabalhos (ALVES; PARENTE, 2019; PARENTE; ALVES, 2019).

Os licenciandos experimentaram, eles próprios, formas diferenciadas de comunicação, ao realizarem atividades semelhantes aos da sua futura atuação profissional. O tema também proporcionou o exercício e desenvolvimento de vários conteúdos procedimentais, tais como pesquisar sobre um assunto, entrevistar especialistas, sistematizar informações, editar vídeos, entre outros.

Imaginamos que algo semelhante ao que vivenciaram no tema LCI (e em outros temas da LIECML) os licenciandos poderão fazer com seus alunos. Eles poderão escolher assuntos relacionados ao contexto local, com os quais as crianças tenham experiências. Instiga-las a relacionar aspectos naturais e culturais implicados em cada assunto. Favorecer a comunicação dialógica com elas e entre elas. Ensejar o exercício de diferentes formas de comunicação, como o relato de experiência, conversas, entrevistas e falar em público. Também exercitar a leitura e escrita, usando diferentes gêneros textuais como as histórias, lendas, poesias, relatórios, receitas e regras de jogos.

Além de formar o professor, relacionando os conteúdos estudados com suas futuras práticas profissionais, pensamos que a experiência de Soure corrobora com as ideias de Gatti (2013, p. 53), quando argumenta que a sociedade exige um novo paradigma em educação, que, entre outras exigências, "solicita cada vez mais que o profissional professor esteja preparado para exercer uma prática educativa contextualizada, atenta às especificidades do momento, à cultura local e ao alunado diverso em sua trajetória de vida e expectativas escolares". 
Por último e talvez mais importante, pelo menos de nosso ponto de vista de formadores de professores, o tema proporcionou a aprendizagem e/ou desenvolvimento de atitudes de valorização da natureza e cultura local, fortalecendo a identidade cultural, a autoestima, a escolha profissional, os vínculos afetivos entre colegas e o sentimento de competência, desde a primeira etapa da licenciatura. Evidente que isto só foi possível pelo trabalho integrado de todos os temas desenvolvidos nesta etapa, produto de uma cultura institucional partilhada pelos professores formadores da LIECML, que transmite para os alunos certos princípios éticos e pedagógicos, como a valorização do estudante, de sua cultura, sua linguagem e seus conhecimentos.

Em resumo, ao narrar e analisar a experiência de ensinar Linguagem e Conhecimento I para a turma de licenciandos, em Soure, produzimos os seguintes sentidos: 1) é possível trabalhar na formação inicial de professores com um tema teórico, mas ainda em uma perspectiva de simetria invertida, usando um conteúdo dos anos iniciais, de forma contextualizada, 2) a contextualização permite valorizar a identidade cultural e a história pessoal dos licenciandos, mobilizando suas emoções e favorecendo a produção de sentidos subjetivos, que constituem a motivação para aprender e planejar o próprio ensino, 3) o planejamento das atividades e a construção de recursos didáticos, implica a imaginação e o pensamento, que são desenvolvidos no diálogo com o professor formador, com os colegas e com os sujeitos participantes das pesquisas realizadas, 4) O diálogo contribui para o desenvolvimento de vínculos afetivos, competências docentes e autonomia dos futuros professores.

\section{Agradecimentos e apoios}

Agradecemos à turma da LIECML de Soure/PA, que compartilhou conosco esta experiência.

\section{REFERÊNCIAS}

ALVES, J. M.; PARENTE, A. G. L. Aprendizagem como produção subjetiva e ensino por pesquisa: uma tentativa de aproximação. In: II Simpósio nacional de epistemologia qualitativa e subjetividade, 2019, Brasília. Anais eletrônicos... Campinas, GALOÁ, 2019. Disponível em: https://proceedings.science/sneqs-2019/papers/aprendizagem-como-producaosubjetiva-e-ensino-por-pesquisa--uma-tentativa-de-aproximacao. Acesso em: 27 fev. 2020.

ANDRÉ, A. Formar o professor pesquisador para um novo desenvolvimento profissional. In: ANDRÉ, M. (org.). Práticas inovadoras na formação de professores. Campinas, SP: Papirus, 2016, p. 17-34. 
BRASIL. Ministério da Educação. Resolução CNE/CP nº . 1, de 18/02/2002. Institui Diretrizes Curriculares Nacionais para a Formação de Professores da Educação Básica, em nível superior, curso de licenciatura, de graduação plena. Brasília: 2002. Disponível em: http://portal.mec.gov.br/seesp/arquivos/pdf/res1_2.pdf. Acesso em: 25 jan. 2014.

CONNELLY, F. M.; CLANDININ, D. J. Pesquisa narrativa: Experiência e História em Pesquisa Qualitativa. Trad. Grupo de Pesquisa narrativa e Educação de Professores ILEEL/UFU, Uberlândia: EDUFU, 2011.

CONTRERAS, J. A autonomia de professores. São Paulo: Cortez, 2002.

CORTELLA, M. S. Conteúdo e conhecimento. In: PROVOCAÇÕES FILOSÒFICAS, 2017. Disponível em: https://www.youtube.com/watch?v=SargvlQPWNk. Acesso em: 20 de março 2017.

CUNHA, P.; MONTANARI, V. Evolução do Bicho-Homem. São Paulo: Moderna, 1995.

FONTANA, R.A.C. A elaboração conceitual: a dinâmica das interlocuções na sala de aula. In: SMOLKA, A. L. B.; GÓES, M. C. R. (Orgs.). A linguagem e o outro no espaço escolar: Vygotsky e a construção do conhecimento. Campinas: Papirus, 1993, p. 132-134.

GATTI, B. A.; BARRETTO, E. S. S.; ANDRÉ, M. E. D. A.; ALMEIDA, A. P. C. A. Professores do Brasil: novos cenários de formação. Brasília: UNESCO, 2019.

GATTI, B. A. Educação, escola e formação de professores: políticas e impasses. Educar em Revista, 2013, p. 51-67. Disponível em: http://www.scielo.br/pdf/er/n50/n50a05.pdf. Acesso em: 04 abr. 2018.

GONZÁLEZ REY, F. La subjetividade: su significación para la ciencia psicológica. In: FURTADO, O.; GONZÁLEZ REY, F. (Orgs.) Por uma epistemologia da subjetividade: um debate entre a teoria sócio-histórica e a teoria das representações sociais. São Paulo: Casa do Psicólogo, 2002, p. 19-42.

GONZÁLEZ REY, F. L. A imaginação como produção subjetiva: as ideias e os modelos da produção intelectual. In: MARTÍNEZ, A. M.; ÁLVAREZ, P. (Orgs.) O sujeito que aprende: diálogo entre a psicanálise e o enfoque histórico-cultural. Brasília: Liber Livro, 2014, p. $35-61$.

JOSSO, M. C. Da formação do sujeito...Ao sujeito da formação. In: NÓVOA, A.; FINGER, M. (Orgs.) O método (auto) biográfico e a formação. Natal: EDUFRN; São Paulo:

PAULUS, 2010, p. 59-79.

LEAKEY, R. A Origem da Espécie Humana. Rocco: Rio de Janeiro, 1995.

LURIA, A. R. Pensamento e linguagem: as últimas conferências de Luria. Porto Alegre: Artes Médicas, 1987. 
MITJÁNS MARTINEZ, A.; GONZÁLEZ REY, F. Psicologia, Educação e Aprendizagem Escolar: avançando na contribuição da leitura cultural-histórica. São Paulo: Cortez Editora, 2017.

MORAES, M. C. Sentidos subjetivos de sustentabilidade e sua docência para professores em formação. 2015. 249 f. Tese (Doutorado) - Universidade Federal de Mato Grosso, Universidade Federal do Pará, Universidade do Estado do Amazonas, Rede Amazônica de Educação em Ciências e Matemática, Programa de Pós-Graduação em Educação em Ciências e Matemática, Cuiabá, 2015. Disponível em:

https://www.ufmt.br/ppgecem/arquivos/ee9523eecc26c24c40c518581d322906.pdf. Acesso em: 16 jan. 2020.

MORTIMER, E. F.; SCOTT, P. Atividade Discursiva nas Salas de Aula de Ciências: Uma ferramenta sociocultural para analisar e planejar o ensino. Investigações no Ensino de Ciências. v. 3, 2002, p. 283-306. Disponível em: https://www.if.ufrgs.br/cref/ojs/index.php/ienci/article/view/562. Acesso em: 20 jan. 2009.

OLIVEIRA, A. S.; BUENO, B. O. Formação às avessas: problematizando a simetria invertida na educação continuada de professores. Educação e Pesquisa. [online], v. 39, n. 4, p.875890, out./dez. 2013. ISSN 1517-9702. Disponível em:

http://www.scielo.br/pdf/ep/v39n4/en_aop992.pdf. Acesso em: 20 de jan. 2017. Doi: https://doi.org/10.1590/S1517-97022013005000011.

OLIVEIRA, R. J. F. Alcances, possibilidades e impactos de metodologias em educação patrimonial ambiental. 2010. 198f. Dissertação (Mestrado) - Universidade Federal do Pará, Núcleo Pedagógico de Apoio ao Desenvolvimento Científico, Programa de Pós-Graduação em Educação em Ciências e Matemáticas, Belém, 2010. Disponível em: https://drive.google.com/file/d/0Bxa8Ai93RdHQLWNLa0h5b1ZSY00/view. Acesso em: 15 mai. 2018.

PARENTE, A. G. L; ALVES, J. M. Aprendizagem em ciências como produção subjetiva de cultura científica escolar. In: XVIII ENEC - Encontro Nacional de Educação em Ciências, III ISSE - International Seminar of Science Education - Educação em Ciências: cruzar caminhos, unir saberes, 2019, Porto, Portugal. Anais eletrônicos... Disponível em: https://enec2019.fc.up.pt/storage/app/media/ENEC-Abstract-Book.pdf. Acesso em 27 fev. 2020.

SANTANA, A. R. O ambiente no olhar de alunos em diferentes momentos de escolarização. 2004. 90 f. Dissertação (Mestrado) - Universidade Federal do Pará, Núcleo Pedagógico de Apoio ao Desenvolvimento Científico, Programa de Pós-Graduação em Educação em Ciências e Matemáticas, Belém, 2004. Disponível em: http://repositorio.ufpa.br/jspui/bitstream/2011/2449/1/DissertacaoAmbienteOlharAlunos.pdf. Acesso em: 15 mai. 2018.

SCARPA, D. L.; TRIVELATO, S. L. F. Aula de ciências sob um olhar vygotskyano e bakhtiniano: "será que golfinho e baleia é peixe?" In: III Encontro de Pesquisa em Educação em Ciências. Anais do III ENPEC - Encontro de Pesquisa em Educação em Ciências, 2001. Disponível em: http://abrapecnet.org.br/enpec/iii-enpec/o30.htm. Acesso em: 15 mar. 2018. 
UNIVESP. O que é linguagem? (1/2) 2008 (10m55s). Disponível em:

https://www.youtube.com/watch?v=I1Zusz_3e8. Acesso em: 17 de maio 2012.

VYGOTSKY, Lev Semyonovich. A formação social da mente. São Paulo: Martins Fontes, 1984.

VYGOTSKY, Lev Semyonovich. Pensamento e linguagem. São Paulo: Martins Fontes, 1987.

Submetido em: 20 de fevereiro de 2020 .

Aprovado em: 01 de março de 2020. 